\title{
Challenges and opportunities in building health research capacity in Tanzania: a case of the National Institute for Medical Research
}

\author{
STEPHEN M. MAGESA ${ }^{1,2,3} 3^{*}$, BONARD MWAPE ${ }^{3}$ and LEONARD E.G. MBOERA ${ }^{4}$ \\ ${ }^{1} R T I$ International, Centre for Strategic Malaria Solutions, Global Health Group, Nairobi, Kenya \\ ${ }^{2}$ National Institute for Medical Research, Amani Research Centre, Muheza, Tanzania \\ ${ }^{3}$ Eastern and Southern African Management Institute, Arusha, Tanzania \\ ${ }^{4}$ National Institute for Medical Research, Headquarters, Dar es Salaam, Tanzania
}

\begin{abstract}
Capacity building is considered a priority for health research institutions in developing countries to achieve the Millennium Development Goals by 2015. However, in many countries including Tanzania, much emphasis has been directed towards human resources for health with the total exclusion of human resources for health research. The objective of this study was to systematically investigate the capacity building process for the Tanzanian National Institute for Medical Research (NIMR) over a 30-year period and identify the challenges and opportunities in creating a critical mass of multi-disciplinary research scientists that is required for achieving the intended health benefits. A desk review of personnel database was conducted for information covering 1980-2009 on academic qualifications, training, research experience and research output. The current staff curriculum vitae (CV) were reviewed to gather information on researchers' employment record, training, training support, area of expertise and scientific output. Interviews were conducted with a cross section of researchers on capacity development aspects using a self-administered questionnaire. In-depth interviews were also conducted with the current and former NIMR Management to seek information on capacity development challenges. A review was also done on staff personal files, annual reports, strategic plans and other occasional documents. A total of 163 CV were assessed; of these, 76.7\% (125) were for Research Scientists (RS), 20.9\% (34) Laboratory Technologists (LT) and 2.4\% (4) for System Analysts. The Institute had 13 research scientists upon its establishment. Since 1980, NIMR has recruited a total of 185 Research Scientists. By 2009 , NIMR had a total scientific workforce of 170 staff (RS= 82.4\%; LT= 17.6\%). Of the $140 \mathrm{RSs}, 37$ (26.4\%) were first degree; 77 (55.5\%) second degree while $26(18.6 \%)$ were $\mathrm{PhD}$ degree holders. Of the total of 78 researchers interviewed, 55 (70.5\%) indicated to have accessed postgraduate training through their personal efforts and 23 through institutional arrangement. Sixty (77\%) respondents were satisfied with their tenure at NIMR. Seventy (89\%) indicated that they had not at any point considered leaving NIMR. Most (79\%) research scientists were recruited while holding a first degree, a few (17\%) with second degree while only one (0.7\%) holding a PhD degree. NIMR has experienced a research scientist attrition rate of $17.5 \%$. Staff retention factors included availability of training opportunities; passion for conducting research; and good career prospects. Despite having a training programme, the institute has never at any moment been able to hold its own training resources. Being a public research institution, NIMR receives its core funding from the government of the United Republic of Tanzania. The bulk of the funding appears to be spent on personnel emoluments that take up to $85 \%$ (mean $=66 \%$ ) of the allocated budget. In conclusion, the current NIMR's research capacity building is dependent mainly on foreign funding and personal initiatives. There is an urgent need to increase local funding for capacity building and conduct of research. A programme should be put in place to ensure sustainability of the capacity building process.
\end{abstract}

Keywords: health research, institution, human resource, capacity building, output, priority, Tanzania

\section{Introduction}

The history of health research in Tanzania goes back to the colonial periods of Germany East Africa and Tanganyika Territory. Under colonial rule, development of local research manpower was unimportant and locals were largely confined to serving at best as clerks and commonly as laboratory attendants. Research positions in the research institutions were exclusively reserved for the white colonial masters. Until mid 1970s, health research in Tanzania was managed under the auspices of the East Africa High Commission through the East African Medical Research Council. Following the break-up of the East African Community in 1977, Tanzania, like its two

* Correspondence: Stephen M. Magesa; E-mail: smagesa@hotmail.com / smagesa@nb.rti.org 
partner states, assumed responsibility over the health research institutions that were located in the country - leading to the establishment of the National Institute for Medical Research (NIMR) by an Act of Parliament No. 23 of 1979 (URT,1979).

NIMR being an institution in the developing world has not been spared by inadequate health research resources. Human resource for health research is considered as the most important resource ingredient. Building the capacity to carry out multidisciplinary research is considered a priority for health researchers if developing countries like Tanzania are to achieve the Millennium Development Goals by 2015 (Haines, 2003; Lee et al., 2004). However, emphasis has been directed towards human resources for health $(\mathrm{HRH})$ with the total exclusion of human resources for health research (HRHR). Very often "research" is only mentioned in the context of either academic or research and development institutions, but human resources for health research are not given attention at all (Ijsselmudien, 2007). Like in other developing countries, there is a paucity of information on HRHR in Tanzania, leading to a situation where HRHR are not planned for in a meaningful manner, not measured nor monitored, nor specifically resourced.

Cognizant of the situation, the global ministerial forum on research for health has emphasized the need for developing HRHR as a means for sustainable development (The Bamako Call to Action on Research for Health, 2008). The Algiers Declaration of 2008, on the other hand commits African governments to work towards strengthening national health research systems, national information and knowledge management through optimization of investments. Countries are expected to support development of human resources through training and access to scientific information. In addition they are to allocate at least $2 \%$ of national health expenditure and at least $5 \%$ of external aid for health to research and research capacity building and invest more in research aimed at improving health systems. It emphasizes the need to develop a critical mass of focal persons and well-trained national researchers in various disciplines of health research (WHO, 2009).

After 50 years of independence and 30 years of establishment the National Institute for Medical Research, Tanzania has not been able to build a critical mass of health researchers that are capable of conducting multidisciplinary research that will possibly lead to the achievement of Millennium Development Goals (MDGs) by 2015. It was the objective of this study to systematically investigate the capacity building process for the National Institute for Medical Research over a 30-year period and and identify the challenges and opportunities in creating a critical mass of multi-disciplinary research scientists that is required for achieving the intended health benefits. Specifically, the study aimed to (i) establish the current HRHR capacity of NIMR; (ii) track research capacity development processes and identify challenges encountered in trying to create a critical mass of researchers; and (iii) analyze the prevailing HRHR development plans and propose strategies for accelerated achievement of a critical mass of scientists.

To address these specific objectives, a number of questions were raised: (i) What is the current HRHR capacity at NIMR in terms of numbers, skills mix and expertise? (ii) Is the current HRHR capacity sufficient to enable it to adequately address the MDGs and its mandate as spelled out in the NIMR Act? (iii) Is the current HRHR capacity sufficient to enable it to adequately respond to the current Institutional strategic plan? (iv) Are there capacity development plans in place to address the HRHR needs of the institute; and (v) how is the institutional health research capacity building process being funded? This study intended to analyse the interplay between these factors in determining the country's health research capacity such that strengths, weaknesses and opportunities for improvement of the health research capacity building processes are identified and addressed. This study is expected to contribute towards an understanding of the HRHR situation of the National Institute for Medical Research and propose the best way possible in building health research capacity for the country's sustainable economic development. 


\section{Materials and Methods}

\section{National Institute for Medical Research, Tanzania}

The Tanzania National Institute for Medical Research was established by an Act of Parliament No. 23 of 1979 (URT, 1979) and became operational in 1980. The Institute mandated among other things: (a) to carry out, and promote the carrying out of medical research designed to alleviate disease among the people of Tanzania; (b) to carry out research into various aspects of local traditional medical practices for the purpose of facilitating the development and application of herbal medicine; (c) in cooperation with the Government or any person or body of persons, to promote, or provide facilities for, the training of local personnel for carrying out scientific research into medical problems; (d) to monitor, control and coordinate medical research carried out within Tanzania, or elsewhere on behalf of or for the benefit of the Government of Tanzania, and to evaluate the findings of that research; (e) to establish a system for the registration of, and to register, the findings of medical research carried out within Tanzania, and promote the practical application of those findings for the purpose of improving or advancing the health and general welfare of the people of Tanzania; and ( $f$ ) to establish and operate a system of documentation and dissemination of information on any aspect of the medical research carried out by or on behalf of the Institute.

\section{Data collection}

The methodology used in this study adopted the health research capacity matrix developed by COHRED (Montorzi et al., 2009). To establish the current HRHR capacity of NIMR, a desk review of research personnel database was conducted for information on academic qualifications, training, research experience and research outputs in terms of publications. A review of research personnel data was obtained from the Human Resources Department and it covered a period from 1980 to 2009. The current curriculum vitae (CV) of staff were also reviewed to gather information for each researcher on employment record, training, training support, area of expertise and scientific output. For the purpose of this study, researchers included those employed as research assistants, research scientists, health laboratory technologists and systems analysts.

Interviews were conducted with a cross-section of researchers on capacity development aspects. Scientists and technologists were categorized (based on the institutional scheme of service) into three levels; that of junior, mid career and senior scientists. For scientists, cadres from Research Assistant to Research Scientist III were categorized as junior scientists. From Research Scientist 1 to Senior Research Scientist I as mid-career scientists and from Principal Research Scientist to Chief Research Scientist were categorized as Senior Scientists. As for the technologist cadre, Health Laboratory Technologist III to Health Laboratory Technologist I were categorized as junior technologists. From Senior Health Laboratory Technologist III to Senior Health Laboratory Technologist I as mid-career technologists while from Principal Health Laboratory Technologist to Chief Health Laboratory Technologist as Senior Technologists. A sample of two staff of each category, from each of the NIMR centres was interviewed. At the time of this exercise, NIMR was made up of six centres. Since there were a few Systems Analysts, only one from each centre was interviewed.

In addition, in depth interviews were conducted with the current and former NIMR Director Generals, Director of Finance and Administration, Director of Research Coordination and Promotion, Director of Information Technology and Communication, Centre Directors and Principal Administrative Officer to seek their experiences and opinion on capacity development challenges. Additional information on personnel was obtained from the Human Resources Department where a database with information on current and old staff is maintained. The database provided detailed information on name, designation, date of birth, date of first appointment, salary scale and date of last promotion. 
A review was also made on some other additional information from staff personal files, institutional annual reports, strategic plans and other occasional documents. Financial data was made available through annual reports, strategic plans and other resources made available by the NIMR management. A self administered questionnaire was sent out to 85 staff requesting information through 19 questions.

\section{Data analysis}

Data was entered onto computer using Epi-Info database. Double entry was made by two data entry clerks and the two databases cross-checked for inconsistencies. Data cleaning was done and where necessary verification of information was done on the original data sheets. Analysis was done using STATA version 8.0 (Stata Corp. LP, TX, USA).

Since the study has adopted the COHRED matrix approach, the following parameters were used as outcome measures in assessing the case study: (i) Recruitment, training, rewarding and retention of research staff; (ii) Setting of institutional research priorities; (iii) Partnerships, collaborations and networks developed; (iv) Establishment of research infrastructure; (v) Research performance in terms of scientific research publications in peer reviewed journals; (vi) Financing of Health Research and capacity building; (vii) Development of Institutional capacity for Monitoring and Evaluation of research activities. Each of these datasets from the above sources was analyzed and where necessary validation was done by triangulation with other data-sources.

To track development in capacity building, data collected was broken down into periods of ten years beginning in 1980 . The tracking focused on number of scientists employed, number of scientific staff trained, number of publications, capacity of research laboratories at research centres and levels of staff attrition.

\section{Results}

\section{Initial capacity building endeavours}

The Institute had 13 research scientists upon its inception, most of them inherited from the former East African Research Council Institutions. Among these few, it was only the first Director General, Prof. Wen Kilama who was a PhD holder. The low number of scientific staff when NIMR was established resulted from the fact that most scientists during the East African Community days were from Kenya, Uganda and UK. Following the break-up of the community, all of them returned to their respective countries except one Ugandan. As the first Director General rightly put it during the interview; "it was very unfortunate that the institute was established in 1979 which was also the beginning of what came to be known as Africa's lost decade" (Prof. W.L. Kilama). He added that "The first cheque from the Ministry of Health meant for establishing the institute for the first quarter of the year was worth TShs 30,000.00 (c. US\$6,000.00 at that time). This was to cover all staff salaries, utilities, running of vehicles and renovation of the dilapidated buildings that were provided for the Institute head offices. To put it simply, the government had no money to spare for the institute"

The very demanding task for building research capacity was obvious right from the beginning. Understanding that the government simply had no money, the Director General had to look outside for support in building capacity for the institute. The first call was made to the World Health Organization/World Bank Programme for Research on Tropical Diseases (WHOTDR). There was good response with a team being sent from Geneva to carry out a needs assessment for the Institute. This resulted into the first major grant worth US\$200,000 in 1982. It was this grant that enabled research activities to be initiated by NIMR.

The very initial challenge that the institute faced was lack of potential candidates on the job market. In 1982, there was only one university in the country, the University of Dar es Salaam. The university produced no more than 20 medical and less than 50 life science graduates per year. In order to build a strong scientific base, the institute set very high criteria for researchers 
to be employed. This required one to qualify with a first class or upper second class degree in order to be considered for a research position. New employees had to be on probation for 12 months (versus six months for public service). This decision created a very stiff competition for the few highly competent candidates between NIMR and other employers, including the University itself. The early years found NIMR losing out to other competitors mainly due to low awareness to research as a career in addition to the comparatively low remuneration that NIMR could offer.

\section{Current Human Resources for Health Research Capacity}

Over the years, NIMR has recruited a total of 185 research scientists. At the time of this study, NIMR had a total scientific and technical workforce of 170 staff. Research Scientists accounted for $82.4 \%$ (140) while Laboratory Technologists accounted for $17.6 \%$ (30) of the scientific staff. Among these there were 30 female Research Scientists and 2 female Laboratory Technologists making up $20 \%$ of the scientific workforce. Of the 140 Research Scientists, 37 (26.4\%) were first degree holders; 76 (55.5\%) second degree holders while 26 (18.6\%) were PhD degree holders.

The results show that most staffs (79\%) were recruited while holding a first degree, a few (17\%) with second degree while only one (0.7\%) holding a PhD degree. Fifty-three staff recruited with first degree had a second degree while the other 21 had PhDs at the time of this study. A total of four staff recruited with a second degree are now PhD holders; two Diploma and 1 Certificate holder at time of recruitment are now second degree holders. A total of 37 staff recruited with a first degree has not been able to acquire additional qualifications since recruitment. Considering those who had left NIMR for whatever reason, 11 had first degree, 16 second degree while 18 left at a time when they already acquired PhD qualifications. These results show that NIMR has been able to successfully support its' staff to train to high academic qualifications.

Table 1: Total number of staff recruited, those present during the survey, resigned, dead, retired and dismissed since 1980

\begin{tabular}{lllllll}
\hline $\begin{array}{l}\text { Staff } \\
\text { cohort* }\end{array}$ & Recruited & Present $^{\S}$ & Resigned & Dead & Retired & Dismissed \\
\hline $1980-1989$ & 45 & 16 & 17 & 7 & 5 & 0 \\
$1990-1999$ & 53 & 43 & 6 & 2 & 0 & 2 \\
$2000-2009$ & 87 & 81 & 5 & 0 & 0 & 1 \\
Total & 185 & 140 & 28 & 9 & 5 & 3 \\
\hline
\end{tabular}

*- Refer to cohorts of research scientists categorised by year of recruitment

$\S$ Refer to number of research scientists still in employment with NIMR by December 2009

Despite being able to train its staff, NIMR has faced a number of challenges in ensuring appropriate training is provided to its staff. The Institute has a training programme, however, it had never at any moment been able to hold its own training resources. It has depended entirely on overseas support for its staff training through bilateral or multilateral agreements and recently through funded research programmes. This has made it almost impossible for NIMR to stick to its training programme and sometimes leading to staff going for training that are not of priority to the institute. So far most training during the first decade (1980-1989) was supported through WHO/TDR institutional support grants, Swiss Development Cooperation, British Council and the Swedish International Development Agency/Secretariat for Research Cooperation (Sida/SAREC).

\section{Training opportunities and job satisfaction}

A total of 163 curriculum vitae of scientific staff were accessed from the NIMR records. These included staff in current and previous employment. Of the $163 \mathrm{CV}, 76.7 \%$ (125) were for Research Scientists, $20.9 \%$ (34) Laboratory Technologists and 2.4\% (4) for Systems analysts. A total of 78 
questionnaires were administered to a cross-section of selected scientific staff. Fifty-five (70.5\%) respondents indicated that they did access postgraduate training through their personal efforts and only 23 got such opportunities through institutional arrangement with collaborators. A good proportion of respondents (45\%) were not aware of the existence of the NIMR training programme, possibly because it has not been functional.

Sixty (77\%) respondents indicated to be satisfied with their tenure at NIMR, with a small proportion expressing poor job satisfaction. More interesting were the responses to the question on whether the respondents had ever considered leaving NIMR for a different employer. Seventy (89\%) indicated that they had not at any point considered leaving NIMR whereas eight (11\%) had at some point considered leaving NIMR. Regarding motivating factors keeping most staff at NIMR, the three reasons that came up more frequently included availability of training opportunities; passion for conducting research; good career prospects with open competition and improved remuneration.

The late 1980 s to early 1990 s were difficult with hardly a handful of training opportunities coming by. This was followed by a change in mid-1990s when a broader opportunity opened up with more potential funders for research and training. Whereas the first decade was characterised by isolated individual training scholarships, beginning in the mid-nineties this acquired a different approach where more training opportunities were available through major research programmes that were developed between NIMR and its collaborators. This opened up with programmes that had multiple training opportunities such as the Enhancement of Research Capacity (ENRECA) Programme funded by Danish International Development Agency (DANIDA); Gates Malaria Partnership funded by Bill and Melinda Gates Foundation; the Joint Malaria Programme initially funded by the British Medical Research Council and later by multiple funders including the pharmaceutical industries; Tanzania - Netherlands Research on AIDS (TANERA)/Tanzania - Netherlands Support on AIDS (TANESA) programmes funded by the Netherlands Government; Bergen University Training Agreement funded by NORAD; Mwanza Intervention Trials Unit (MITU) funded by the Medical Research Council of UK.

\section{Recruitment, compensation and retention of Human Resources for Health Research}

Traditionally, the recruitment of human resources for health research at NIMR has been based on the institute being an equal opportunity employer. The recruitment process has been open and transparent where advertisements are put in the media and potential applicants are invited to apply. The applicants are then shortlisted and invited for interviews that are conducted by a panel which often brings on board experts from outside NIMR. Research scientists are initially recruited on a 12-month probation period, after which they may be confirmed on permanent and pensionable terms. Recruitment is guided by the NIMR scheme of service and requirements for personnel as identified by the Institute. Of recent, it has been necessary for NIMR to request for permission from both the Central Establishment and Treasury for funding of the positions. This has created a major hitch since it has always been difficult for Treasury to approve all NIMR placement requirements due to shortage of funding.

Analysis of the entry qualifications of staff showed that recruitment of the first cohort from 1980 - 1999 was very stringent, sticking to those candidates with first or upper second class or with non-classified degrees such as medical and veterinary medicine. Data showed that some years would pass without any recruitment if highly qualified candidates were not available on the market. Recruitment of the latter cohort 2000-2009 did not seem to be that stringent as it included less qualified staff, despite the job market having grown bigger due to a large increase of university graduates compared to earlier years. There were also indications of poor recruitment planning leading to massive recruitment of 29 medical doctors (out of 40 recruits) between 2005 and 2008 purportedly with the intention of strengthening clinical research. A quick analysis shows that at the time of the survey, hardly five of these recruits were interested in clinical research and were currently focussing on other research areas. With the increasing 
number of research projects, it has been necessary to hire additional research staff on short term contracts due to difficulties in obtaining clearance for formal recruitment from the Treasury. This has provided another opportunity for observing young research assistants for their potential as future lead researchers.

The NIMR compensation offered to research scientists have been relatively poor until recently when the implementation of the harmonised public researcher scheme of service coordinated by Tanzania Commission for Science and Technology was put in place in July 2008. Prior to these changes, the NIMR compensation scheme was based on that of parastatal organisations that included mostly state owned income generating institutions. Such institutions were capable of putting in place additional incentives that improved compensation for their staff. This made compensation to NIMR scientists much inferior than that of their counterparts in parastatal organisations as well as central government employees. As indicated by some interviewees, "we had to remain in NIMR employment those days not for money, but simply because of our passion for scientific research".

The recent changes through the scheme of service for researchers aimed at harmonising and improving compensation for scientific staff employed in the public research institutions. The scheme has put researchers almost at par with university academic staff in order to increase competitiveness between the two types of institutions. Currently, compensation for research scientists range from TShs $841,340.00$ (US\$561) per month for a newly recruited Research Assistant up to TShs 3,730,590.00 (US\$2,487) per month for Chief Research Scientist. Promotion from Research Assistant to Chief Research Scientist is purely on merit, based on training and publications by the respective scientist. Efforts to put in place a formal retention scheme for NIMR staff has been made with the development of a staff retention scheme in 2006. The very elaborate scheme was approved by the NIMR Council, but could not be implemented due to lack of funding.

The analysis showed that over the 30-year period, NIMR has experienced a research scientist attrition rate of $17.5 \%$. This translates to a mean of $0.6 \%$ attrition rate per year. Breaking down the analysis by cohort shows that there was a high attrition in the first cohort with an overall attrition rate of $37 \%$ or $1.2 \%$ per annum. The second cohort has an overall attrition rate of $15 \%$ or $0.78 \%$ per annum while the third cohort has an overall attrition rate of $6.8 \%$ or $0.75 \%$ per annum.

\section{Research Output}

The standard measure of a research organizations' output has traditionally been in terms of number and quality of publications; grants awarded and more recently in terms of patents registered. There is currently no formal register for the few patents that NIMR research scientists have participated in developing and registering in collaboration with foreign partners. In addition, detailed information on research grants won by NIMR scientists was not found to be comprehensive enough for the purpose. The number and to a lesser extent the quality of scientific publications was therefore chosen as the best measure of research output for NIMR scientists.

A total of 646 scientific articles were published by NIMR scientists alone or in collaboration with partners between 1980 and 2009 (Figure 1). The number of publications has likewise grown steadily with the number of research scientists, from 4 publications a year with a peak in 2001 with 57 publications. Despite the increase in number of publications by the years, the output has not at all been that encouraging when considered in terms of per capita publications. The best performance was achieved in year 2001 with 0.69 publications per scientist per year! 


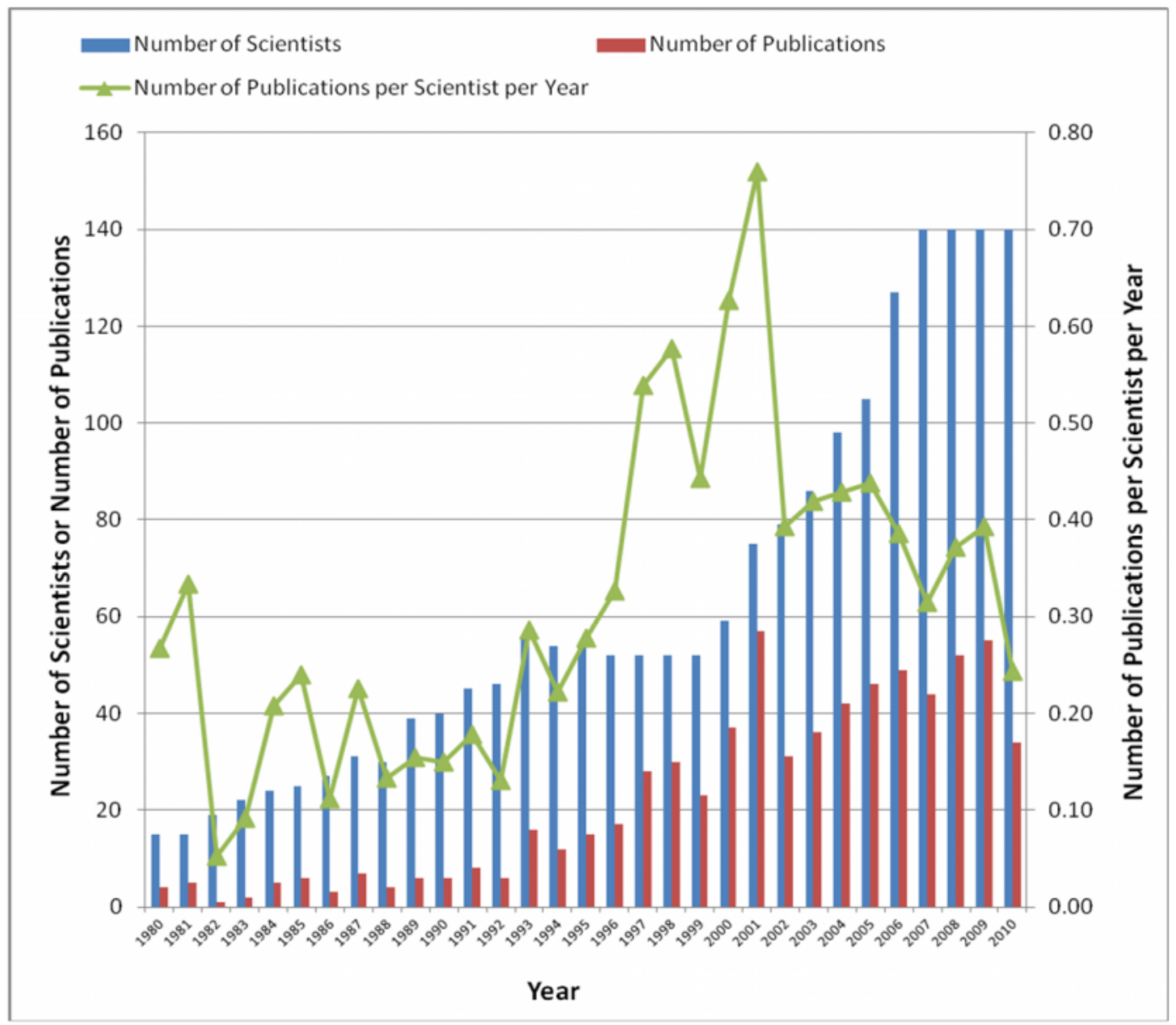

Figure 1: Trends in number of research scientists and number of journal publications per-capita per year

Articles were found to be published in some very reputable international peer reviewed journals. The journals that published over a total of ten or more articles by NIMR scientists over the period included Acta Tropica, AIDS, American Journal of Tropical Medicine and Hygiene, Annals of Tropical Medicine \& Parasitology, BMC Health Services Research, BMC Public Health, Journal of Infectious Diseases, Infection and Immunology, Lancet, Malaria and Infectious Diseases in Africa, Malaria Journal, Research Journal of Medical Sciences, Sexually Transmitted Infection, Tanzania Journal of Health Research, Transactions of the Royal Society of Tropical Medicine and Hygiene, Tropical Medicine and International Health and Tropical Medicine and Hygiene.

A few articles have as well appeared in very high impact point journals. These include the British Journal of Ophthalmology, British Journal of Nutrition, European Journal of Clinical Nutrition, Genome, Journal of Immunology, Molecular Biology and Evolution, Science, Molecular Immunology, New England Journal of Medicine, Nature, Parasitology, Proceedings of the National Academy of Sciences USA and Trends in Parasitology.

NIMR has in 1997 established the publication and production of a quarterly peer reviewed journal, Tanzania Journal of Health Research formally known as Tanzania Health Research Bulletin. This journal targets scientists, policy/ decision makers and the general public. The Journal publishes original papers, review articles or short communications on biomedical, health sciences and policy and planning. It has so far provided a popular platform for dissemination of health research information in the country and beyond. 
To enhance scientific communication, NIMR has since 1983 coordinated and hosted an Annual Joint Scientific Conference and occasional symposia. The annual joint scientific conferences are events that provide a forum for researchers, practitioners, trainers, decision and policy makers, media and representatives of special groups to share research results and experiences in issues related to health and health research. The event has over the years become the largest gathering of health research scientists in Tanzania that attracts significant participants locally and from abroad. It has therefore become an important forum for exchange of health research information in the country.

\section{Skills mix}

Right from its establishment, NIMR's focus has been on research towards communicable diseases, mainly parasitic diseases like malaria, schistosomiasis, onchocerciasis, sleeping sickness, lymphatic filariasis and intestinal helminths. Efforts were immediately directed towards HIV/AIDS following the pandemic during the mid-1980s. The decision did make a lot of sense since these communicable diseases were and are still the major public health problems to-date. Despite such a focus, not all essential elements of these diseases have been covered so far. Some cross-cutting disciplines were received late, social sciences and statistics first began to be developed in the early 1990s. Health systems, health economics and health policy, and geographical information systems are still at infancy stage, despite their importance in the success of disease interventions.

Of $163 \mathrm{CVs}$ of research scientists examined, only 39 were bold enough to state clearly their skills and areas of expertise. Most CVs at most provided some outline of "research experience" or "participation in research activities". The few scientists who indicated their areas of competence and from the publications list, indicates NIMR so far has accumulated a wealth of expertise in malaria, tuberculosis, HIV/AIDS, schistosomiasis, neglected tropical diseases and intestinal helminths. There is a wealth of expertise in the epidemiology and control of these diseases, with a budding expertise in basic sciences as modern laboratories are being established. Another rapidly growing area is in clinical research, particularly case management, drug and vaccine trials.

One aspect that appeared limiting was the number and quality of laboratory technologists in NIMR employment. As it is now, whereas NIMR is having a good number of qualified scientists, laboratory technologists are not well trained. The most senior technologists were mere diploma holders albeit without further specialised training. It is as late as in 2008 that two young laboratory technologists completed their first degrees in laboratory sciences. Looking at the numbers, in a situation where there are 140 research scientists ( 26 with $\mathrm{PhD}$ ), there are only 30 laboratory technologists to support them.

\section{Training and mentorship}

The analysis indicates that NIMR is doing very well in getting its staff trained for higher degrees. Out of the current $26 \mathrm{PhDs}$, in service at least 25 (96\%) were trained while with NIMR and 53 out of $76 \mathrm{MSc}$ holders (70\%) were trained while in NIMR employment. Most of the 37 scientists with first degree are those who joined the organisation over the last two to three years. According to the NIMR Director of Finance and Administration; "these are also likely to go for post-graduate training soon". NIMR has in place a training programme for its staff, "however it has been difficult to implement it due to lack of resources" (Principal Administrative Officer).

The Government of Tanzania has over the years, been providing very little funds for training. These resources have been found to be inadequate particularly for PhD training in biomedical sciences which is expensive. The little training resources have therefore been used for cheaper training of non-scientific staff. Almost all training for scientists was therefore funded from foreign sources. This has either been from capacity strengthening grants, bilateral agreements or through open competition scholarships. 
At NIMR's inception, there was a lot of goodwill and the institute had almost open opportunities with very few candidates to take them up. This continued up to the mid to late 1980 s when due to the world economic trends and Africa being in economic doldrums, such opportunities were not easily forthcoming. With the changes in mid-1990s, new initiatives and more research funds to support large research programmes came into being. As a result NIMR got more training opportunities for MSc and PhD through the ENRECA, Mema kwa Vijana, Joint Malaria Programme, Gates Malaria Partnership, Bergen University Training Agreement, Mwanza Intervention Trial Unit, MCTA, Afrique 1, TRHiVE and similar programmes. This change was more convenient for higher degree training since it provided better environment for research training as scholars pursued their training within a structured research programme. Since all these programmes were collaborative, scholars had access to both local and external mentorship that further strengthened the training.

During the interviews, it became apparent that although the first cohort of research scientists got immediate training after recruitment to MSc and PhD levels, they had difficulties in attracting funds and engaging in research activities due to lack of immediate senior scientists to provide mentorship and guidance. They therefore had to "fend for themselves", which was not easy to most of them. Perhaps this contributed to the relatively high staff attrition in that cohort. The few who remained are the current senior scientists who are expected to mentor junior scientists. However, their previous experience has possibly denied them the capacity to be able to deliver as mentors, thus adversely affecting local mentorship of research scientists. Currently, there is however a newly observed trend where senior scientists have over the last five years been actively involved in the supervision of fellow junior scientists for their MSc and PhD training, further promoting mentorship culture in the institute.

\section{Health Research Priorities}

NIMR health research priorities are structurally guided by the Act of Parliament establishing the Institute (URT, 1979) which stipulates the mandate entrusted to the institute in the country's health research portfolio. Another guiding principle is that of the national health research priorities and lately the institutional strategic plans that were crafted and put into use by the NIMR for the first time in 1997 (NIMR, 1997). The country's health research priority setting process is led by NIMR through the Tanzania National Health Research (TANHER) Forum. The first such exercise was conducted in 1992 through a participatory process as detailed by Montorzi et al. (2009). The process sets national priorities for a 5-years' periods to be used by health researchers including NIMR as a platform for their research plans and priorities.

\section{Financing research capacity building}

Being a public research institution, NIMR receives its core funding from the government of the United Republic of Tanzania. Table 2 summarises the amount of funding that NIMR has received from the government over the past ten years (2000/01 to 2009/10). The bulk of the funding appears to be spent on personnel emoluments that take up to $85 \%$ (mean $66 \%$ ) of the allocated budget. Focusing on research funding, the highest was recorded in 2006/07 at 19\% of the allocation. However, very disappointing is the fact that for the past five years (2005/06-2009/10), there has been zero allocation to NIMR for research from the government of Tanzania! Over the years, the NIMR budget was equivalent to $3-6 \%$ of the total budget of the Ministry of Health. It was also noted that NIMR was receiving a budget allocation to run, on behalf of the Ministry of Health, the National Lymphatic Filariasis Elimination Programme. 
Table 2: Government budget allocation (in TShs) for the National Institute for Medical Research from fiscal years 2000/2001 - 2009/2010

\begin{tabular}{|c|c|c|c|c|c|c|c|c|c|c|c|c|}
\hline \multirow[t]{2}{*}{$\begin{array}{l}\text { Financial } \\
\text { Year }\end{array}$} & \multirow{2}{*}{$\begin{array}{l}\text { MoHSW Budget } \\
\text { (Recurrent } \\
\text { Budget Only) }\end{array}$} & \multicolumn{3}{|c|}{$\begin{array}{l}\text { Government Subvention to NIMR } \\
\text { in TShs }\end{array}$} & \multicolumn{8}{|c|}{ Breakdown of Funds distribution to various budget lines (in TShs) } \\
\hline & & $\begin{array}{l}\text { NIMR Budget } \\
\text { Allocation }\end{array}$ & $\begin{array}{l}\% \text { of } \\
\text { NIMR } \\
\text { versus } \\
\text { MoHSW } \\
\text { Budget } \\
\end{array}$ & $\begin{array}{l}\text { Development } \\
\text { Budget }\end{array}$ & $\begin{array}{l}\text { Personnel } \\
\text { Emolument }\end{array}$ & $\%$ & $\begin{array}{l}\text { Other Charges } \\
\text { (Admin) }\end{array}$ & $\%$ & Research & $\%$ & $\begin{array}{l}\text { Maintenance } \\
\text { of Quality } \\
\text { Assurance } \\
\text { Lab/ TANHER } \\
\text { Forum }\end{array}$ & $\begin{array}{l}\text { National } \\
\text { Lymphatic } \\
\text { Filariasis } \\
\text { Elimination } \\
\text { Programme } \\
\end{array}$ \\
\hline $2000 / 01$ & $34,190,000,000$ & $1,896,713,887$ & 6 & $2,647,400$ & $1,239,098,902$ & 65 & $401,171,760$ & 21 & $256,443,225$ & 14 & & - \\
\hline $2001 / 02$ & $42,531,415,000$ & $2,022,949,284$ & 5 & - & $1,425,250,968$ & 70 & $441,545,000$ & 22 & $156,153,316$ & 8 & & - \\
\hline $2002 / 03$ & $51,003,350,600$ & $2,073,747,204$ & 4 & $482,240,000$ & $1,594,413,742$ & 77 & $353,034,899$ & 17 & $126,298,563$ & 6 & & - \\
\hline $2003 / 04$ & $86,422,152,231$ & $2,821,486,238$ & 3 & $342,964,543$ & $1,727,908,394$ & 61 & $645,485,844$ & 23 & $373,092,000$ & 13 & & $75,000,000$ \\
\hline $2004 / 05$ & $104,465,379,200$ & $3,168,573,300$ & 3 & $305,330,311$ & $2,018,573,300$ & 64 & $607,216,824$ & 19 & $542,783,176$ & 17 & & $149,220,000$ \\
\hline $2005 / 06$ & $90,862,748,400$ & $4,716,430,161$ & 5 & $438,304,260$ & $2,316,430,661$ & 49 & $1,332,214,030$ & 28 & $584,216,631$ & 12 & & $400,000,000$ \\
\hline $2006 / 07$ & $195,981,343,000$ & $7,556,681,084$ & 4 & - & $3,756,681,084$ & 50 & $2,010,482,000$ & 27 & $1,457,695,000$ & 19 & & $331,823,000$ \\
\hline $2007 / 08$ & $187,627,787,000$ & $6,048,117,971$ & 3 & - & $4,448,117,971$ & 74 & $903,785,000$ & 15 & 0.00 & 0 & $404,463,461$ & $291,751,539$ \\
\hline $2008 / 09$ & $198,157,615,000$ & $7,918,283,664$ & 4 & $700,000,000$ & $6,223,283,664$ & 79 & $1,096,607,856$ & 14 & 0.00 & 0 & $406,392,144$ & $192,000,000$ \\
\hline $2009 / 10$ & $225,093,792,701$ & $7,319,891,520$ & 3 & $350,000,000$ & $6,223,283,664$ & 85 & $1,096,607,856$ & 15 & 0.00 & 0 & $406,392,144$ & $192,000,000$ \\
\hline TOTAL & $1,216,335,583,132$ & $38,222,982,792$ & 3 & $2,621,486,514$ & $24,749,758,685$ & 65 & $7,791,543,213$ & 20 & $3,496,681,911$ & 9 & $1,217,247,749$ & $1,439,794,539$ \\
\hline
\end{tabular}

Key: MoHSW= Ministry of Health and Social Welfare 
The institute has been able to obtain funding for research and capacity building from foreign sources particularly international funding agencies through open competitions. NIMR has been able to forge links with a number of collaborators with whom they put together applications for research grants that are submitted to various funding bodies. Others have included partnerships through various networks that support research and capacity building activities (Table 3 ). The most recent data over the last two years show that whereas the Government of Tanzania through the Ministry of Health and Social Welfare provided a total core budget of TShs $6,048,117,971$ and TShs 7,918,283,664 in fiscal years 2007/08 and 2008/09, respectively, NIMR and its collaborators mobilised TShs 7,233,354,144 and TShs 8,590,280,130 from external sources during the same periods for research and capacity building. The amounts mobilised by NIMR and collaborators were much higher than those allocated by the government as core funding. It is during the same period also when the government did not allocate to NIMR any funding whatsoever for research activities.

Table 3: Contribution of external funding to research capacity building in comparison to government research support to NIMR

\begin{tabular}{llllll}
\hline $\begin{array}{l}\text { Fiscal } \\
\text { Year }\end{array}$ & $\begin{array}{l}\text { Government } \\
\text { budget } \\
\text { allocation } \\
\text { NIMR (TShs) }\end{array}$ & $\begin{array}{l}\text { Total NIMR annual } \\
\text { expenditure (TShs) }\end{array}$ & $\begin{array}{l}\text { External } \\
\text { funding } \\
\text { (TShs) }\end{array}$ & $\begin{array}{l}\text { research } \\
\text { Government } \\
\text { research support } \\
\text { to NIMR (TShs) }\end{array}$ \\
\hline $\mathbf{2 0 0 7 / 0 8}$ & $6,048,117,971$ & $13,281,472,115$ & $7,233,354,144$ & 0.00 \\
$\mathbf{2 0 0 8 / 0 9}$ & $7,918,283,664$ & $16,508,563,794$ & $8,590,280,130$ & 0.00 \\
TOTAL & $\mathbf{1 3 , 9 6 6 , 4 0 1 , 6 3 5}$ & $\mathbf{2 9 , 7 9 0 , 0 3 5 , 9 0 9}$ & $\mathbf{1 5 , 8 2 3 , 6 3 4 , 2 7 4}$ & $\mathbf{0 . 0 0}$ \\
\hline
\end{tabular}

\section{Discussion}

Research requires a high level of academic qualification for it to be effectively accomplished. Ideally, a researcher should be trained through research training at least up to the level of doctorate degree, followed by intensive mentorship from senior researchers. The fact that the job market had difficulty providing first degree holders, there was an urgent need for the institute to put in place a framework for immediate training of recruited staff.

As health problems becomes more complex due to new, emerging and re-emerging diseases, pandemics such as HIV/AIDS, multi-drug resistance among pathogens, health research is therefore becoming increasingly multidisciplinary. Weaknesses in health systems of most countries' national health systems (NHS) in both developed and developing countries have compounded the situation such that it has become difficult to interrupt disease transmission even when and where effective tools are already available for intervention.

This situation has made it extremely important that research institutions develop and maintain a critical mass of scientists who would be able to address the health problems more effectively. The term "critical mass" is used here to refer to "a size, number or amount large enough to produce a particular result" (Merriam Webster online search Dictionary, 2009). This necessitates research organizations such as NIMR to develop research scientists that cover a broad range of expertise, in sufficient quantities that would enable it to adequately address the countries' health problems. Nchinda (2002) observes a mismatch between the increased disease and health burden and the technical and human capacity of developing countries to either harness the existing knowledge or generate new knowledge to combat these diseases and health problems through research. He considers it extremely important that developing countries such as Tanzania develop indigenous research capacity that would enable them 
undertake studies in their own national settings that would lead to appropriate control strategies. The only sure way of developing and maintaining such a critical mass of researchers is through capacity building.

The National Institute for Medical Research is currently implementing its $3^{\text {rd }}$ Five Year Strategic Plan (NIMR, 2008a). The plan aims at (a) improving translation, dissemination and utilization of research findings (b) strengthening the system of protecting intellectual property and institutional ownership of research findings and (c) improve scheme of service and modify organizational structure so as to develop, motivate and retain research staff. Currently, the major research areas of focus include malaria, sexually transmitted infections, HIV/AIDS, tuberculosis, health systems, schistosomiasis, trypanosomiasis, helminthiases, non-communicable diseases and traditional medicine. Most research carried out by NIMR is guided by the National Health Research Priorities. Despite this diversified research protocol, while the institute is relatively strong in malaria and HIV/AIDS research, is still weak in other research areas (Mboera, 2010).

A number of factors at system, institutional and individual levels have been observed to influence research capacity building. A recent investigation conducted by Barret \& Nakabugo (2008) categorized these into enhancing and limiting factors. Research and innovation has made significant contributions to the development of solutions to health problems and to the advancement of human health worldwide. The nature of research and innovation for health improvement has become increasingly multidisciplinary, interconnected and inter-sectoral. In order to conduct relevant effective research, national institutions ought to build research capacity through developing and retaining a critical mass of scientists who can handle the current challenges. A clear understanding of the current status of HRHR against the impending environment becomes crucial.

The NIMR per capita publication output may sound very dismal. However, it appears to compare favourably with that of the most reputable research institution in Africa; the South African Medical Research Council (SAMRC, 2008). The 2007/2008 Annual Report of the SAMRC registered 705 and 528 peer-reviewed publications in 2007 and 2008, respectively. The SAMRC had a total of 874 staff members of whom 431 were funded through contracts and 443 were baseline funded. This makes the per-capita output estimated at $0.80-1.59$ and $0.61-1.22$ publications per scientist per year for 2008 and 2007, respectively when considering both contract staff and baseline staff or baseline staff only. Despite this parity in per-capita publication output, the SAMRC has an edge over NIMR in terms of innovation and technology transfer whereby in 2007, SAMRC had four new patents registered, two disclosures made and one new start-up company established (SAMRC, 2008). It could be worth noting that, Tanzania is ranked among the best ten countries with high volume of health literature citations in Sub Saharan Africa, South Africa included (Hoffman, 2009). NIMR is known to make a significant contribution to these numbers (Mboera, 2010).

In 1997, NIMR through the Tanzania Health Users' Trust Fund, established Tanzania Journal of Health Research as tool to make relevant and current health information available to scientists, practitioners, policy and decision-makers, as well as the public in Tanzania and beyond. This open-access Journal publishes original and review articles on health research. Over the years, the journal has provided a popular platform for dissemination of health research information in the country and beyond (Mboera, 2010). It is worth noting here that this is an outstanding success since health research is currently the only sector to have an on-line, open access international peer reviewed journal published in the country (Montorzi et al., 2009).

Skills mix in any organization is considered to be a potential solution to improved delivery of expected outcomes. It refers to the combinations of skills among employees that are available at a given specific time (Adams, 1994). In the recent past, skills mix within health research institutions has become increasingly important due to the necessary requirement of conducting multidisciplinary research. The term skill is commonly used interchangeably with the term expertise. However expertise has been referred to as the mechanism underlying the superior 
achievement of an expert (Ericsson et al., 1993). The Webster's dictionary defines an expert as "one who has acquired special skill in or knowledge of a particular subject(s) through professional training and practical experience (Merriam Webster, 2009). It is a term therefore used to describe highly experienced professionals, but has been extended to include individuals who attained their superior performance by instruction and extended practice. The current skills mix among NIMR research scientists has always been a heritage of the old East African Medical Council research institutions whose premises it inherited in 1979 to establish NIMR Research Centres. The centres were disease oriented with Mwanza Centre focusing on schistosomiasis and intestinal helminths, Amani Centre on malaria and other vector-borne diseases, Muhimbili Centre on Tuberculosis, Tukuyu on onchocerciasis and Tabora Centre on sleeping sickness.

Right from establishment, NIMR's focus has been on research towards communicable diseases. However, over the years, the epidemiology of non-communicable diseases is changing rapidly in the country, bringing the diseases towards the level of public health importance (Mfinanga et al., 2011). NIMR is yet to develop expertise in these areas. Despite communicable diseases still being more important there is a danger of the two types of diseases to overlap at some point, leading towards aggravating the disease burden to the Tanzanian community. There is need for NIMR to develop such capacities particularly in cardiovascular diseases, diabetes, mental health, substance abuse, neurological disorders, geriatric disorders, nutrition disorders and diagnostics.

One other area that requires immediate attention is research on maternal and child health. This is still a very weak area in NIMR though it overarches two millennium development goals, namely MDG 4 (Reducing Child Mortality) and MDG 5 (Improving Maternal Health) (United Nations, 2008). If attention and development of research capacity in these areas is not urgently considered, NIMR will lag behind in its contribution towards achieving the MDGs, which will turn out to be a miss-service to the Tanzanian community.

Expertise in data handling and management is still wanting within NIMR, with the exception of Mwanza Centre which has a well developed data management system to support research. Discussion with Centre Directors revealed that this is still an area of concern where more effort ought to be directed. The institute has very few (8) biostatisticians and virtually no data managers to support them. Infrastructure for data handling and management is still very poor. There is a great need to develop such capacities.

One aspect that appears limiting is the number and quality of laboratory technologists in NIMR employment. This is a cadre that ought to work closely and in support of research scientists in their day to day work. Ideally, in a vibrant research environment there should have been more technologists than research scientists. At least each research scientist should be having more than one ongoing research activity, each of which would thus require a technologist to run. The current situation implies that there is either a large number of research scientists that sits idle, or some scientists simply assumes the role of technologist or else, more junior staff such as untrained laboratory assistants are the ones taking up roles of laboratory technologists potentially resulting into poor quality results. This imbalance ought to be corrected.

Other requisite cross-cutting skills that appear important for NIMR to address its mandate fully but are still inadequate include monitoring and evaluation, research ethics, research management and coordination. Important as these skills are, there is only one person trained in medical ethics, one in M\&E and none in research project management. The institute lacks staff dedicated to managing intellectual property rights emanating from institutional research findings. 
Health research is intended to solve practical problems prevailing in the country. It therefore becomes imperative that an assessment is done to understand the prevailing landscape and priorities made. Focussing on priority research areas leads to rational use of resources and immediate impact on health particularly in conformity with achieving the millennium development goals. NIMR health research priorities are structurally guided by the Act of Parliament establishing the National Institute for Medical Research (URT, 1979) which stipulates the mandate entrusted to the institute in the country's health research portfolio. The first country's health research priority setting exercise was conducted in 1992 through a participatory process detailed by Montorzi et al (2009). Tanzania has probably the most elaborate mechanism in setting the national health agenda in Africa. The national agenda provides a firm platform for NIMR to then set its research priorities. The strategic plan provides a set of priorities over a number of years (currently five years) that are subject for revision after every two years. However, this study has observed weaknesses in funding, executing and reviewing of the strategy leading to the institution not being able to achieve the desired level of achievement with each strategy.

Despite having national health research priorities in place since 1992, NIMR did not have its own institutional priorities until 1997 when it crafted its' very first strategic plan (NIMR, 1997). Since then, two more strategic plans have been crafted (NIMR 2002; NIMR 2008 ${ }_{a}$ ). Interview responses from Centre Directors indicated that there was poor strategy implementation due to lack of funding to support the plan. Unfortunately, there was no thorough documented review or evaluation of the strategic plans so far. The current plan, in addition to conducting research in priority areas as guided by the national health research priorities, it also aims at (i) strengthening the system of protection of intellectual property rights and ownership of research findings; (ii) improving translation, dissemination and utilisation of research findings; and (ii) commercialisation of research products.

As it is now, NIMR research activities are prone to being steered away from national priorities depending on the interests of the funding bodies. It is just by coincidence that the interests of the funders may corroborate those on the institutes' priority list. The NIMR often finds itself in a compromising situation to accept conducting research even if they do not exactly conform to national priorities (Uthman, 2009). This situation therefore calls for more national funding for health research in order to be able address those priority areas of interest and hence realise the most benefit to the nation.

During the past 30 years, NIMR appears to have managed to exercise fully all the mandate given to her except for a few areas that are yet to be fully addressed. These include articles 4.(1) d: "to monitor, control and co-ordinate medical research carried out within Tanzania, or elsewhere on behalf of or for the benefit of the government of Tanzania, and to evaluate the findings of that research" and 4.(1) e: "to establish a system for the registration of and to register the findings of medical research carried out within Tanzania, and promote the practical application of those findings for the purposes of improving or advancing the health and general welfare of the people of Tanzania". These are key areas that govern the process of turning research findings into practice, be it policy, product, intervention etc. There are currently no strong structures in place to support these activities, including personnel with the requisite skills to perform the duties associated with such mandate (Mboera et al., 2009). The monitoring and evaluation system is almost non-existent and the registration system of research findings is not functional.

Being a public research institution, NIMR receives its core funding from the government of the United Republic of Tanzania. The health sector in Tanzania is considered a key factor in economic development and is accorded higher status through Cluster II of the National Strategy for Growth and Poverty Reduction (NSGPR) (Government of Tanzania, 2005). It is on record that from 1991 to 2000, the government of Tanzania provided US\$29.5 million as core funding to national health research institutions (Kitua et al. 2002). This scenario has been observed despite the bold and clear statement from the President of the United Republic of Tanzania in 2008 that 
the government was committed to increase state funding for research and development from $0.3 \%$ of the gross domestic product (GDP) to $1 \%$. Financially speaking, this increase of GDP is equivalent to TShs 248 billion up from the current annual funding of TShs 75 billion (Shoo, 2009). We remain optimistic that the situation will change once the plan is implemented and that NIMR will see an increase in research funding from the government.

This study has observed that recruitment of research scientists at NIMR during the first two decades was very stringent such that it resulted in bringing on board a team of very competitive scientists, despite the small labour market prevailing at that time. Realizing that research scientists are not readily available on the job market, NIMR has always strived and succeeded in readily training its scientists with the aim of having all of them acquire at least a research doctorate degree. Support from government has not come by over the years and training remained to be funded entirely from foreign sources. This has made it difficult to observe and adhere to the institutional training programme. Training has become a motivator to most staff and a tool for staff retention. Efforts to put in place a staff motivation and retention scheme was immediately frustrated by lack of resources. Rewards in form of compensation to research scientists have recently improved through a national programme to promote scientific research.

Over the years, NIMR has been able to develop a number of partnerships, albeit with its traditional research partners from Europe. This study has observed an increased number of partnerships and networks beginning in the late 1990s. These partnerships have been very rewarding in terms of winning large grants, accessing training opportunities, building research infrastructure, accessing mentorship for budding Tanzanian scientists as well as building high profile for the institute.

The national policy framework does not seem to be consistent in terms of promoting and supporting health research capacity building. Whereas Vision 2025, National Science \& Technology Policy and NSGPR (Government of Tanzania, 2005) seriously addresses scientific research, the Health Sector Strategic Plan III is silent on health research (MoHSW, 2009). Such inconsistencies in policy frameworks are likely to introduce systemic bottlenecks that could potentially retard research and development processes. It is important that such policy frameworks are revisited and harmonized accordingly.

At inception, NIMR inherited poor research infrastructure that was very rudimentary, made of very basic laboratories at the former East African Community research institutions. Immediate efforts were made to develop research infrastructure with the WHO/TDR research strengthening grant. Further development in this area has resulted to NIMR having modern research laboratory facilities at most of its research centres (Mboera, 2010). New technologies to support research, such as internet connectivity is now available at all research centres and all active research stations. Due to the pace of developing technologies, these will need regular updating and should be considered as a continuous process.

The current findings show that research performed by NIMR still covers a narrow range of disciplines, with emphasis on parasitic and communicable diseases. Indeed this is due to the diseases inflicting a huge burden on the Tanzanian community. The study has observed the need to focus on cross-cutting and supportive disciplines such as health systems, bioinformatics and data management. With the increasing burden of non-communicable diseases, it is also important that more research is directed towards the area. In order to make significant contributions to the Millennium Development Goals, NIMR ought to urgently develop a research agenda on maternal and child health that directly addresses MDG4 and MDG 5. Such a move is considered more rewarding at the moment since resources are readily available. Subsequently, other areas such as non-communicable diseases are also considered important.

The National Institute for Medical Research is a public institution that acts as a health research arm of the Ministry of Health and Social Welfare. It therefore receives its core funding from the treasury of the government of the United Republic of Tanzania. The current study has found that the funding received from the government covers most of the running of the institute 
with a very small proportion going towards direct funding for research. Over a ten years period from 2000/01 to 2009/10, the mean proportion of this allocation has remained below $5 \%$. The last few years from 2006/07 to 2009/10 have witnessed no funding being allocated to NIMR for research. Training of research scientists, which is considered an important component for capacity building has not received any financial support from the national government. It has therefore entirely depended on foreign funding. Likewise, infrastructure development in terms of putting up and equipping laboratories has largely depended on external funding. There is an urgent need to increase local funding for capacity building and research. The level of government funding observed in the last three years has been discouraging. It is extremely important that the situation is reversed if sustainable health research capacity building is to be achieved in the country.

Despite the efforts to collaboratively set priorities, research institutions in Tanzania do not receive adequate core funding from the government that would allow them to do long-term planning, establish and comply with national research priorities, and invest in creating strong research programmes. Similar to our findings, funds allocated for research in Tanzania was reported to be far below the recommended $2 \%$ of the national budgets (Kitua, 2007). Although international donors give support to research, but usually for one-off projects, which they often design and lead. With inadequate local funding of research in Tanzania, international donors are a key source of funding for local researches; and therefore it is not surprising that the same donor agency influence policy making to a large extent (Mboera et al., 2009).

Apart from carrying out health research, NIMR is also mandated to monitor and evaluate health research conducted in Tanzania or on behalf of Tanzania. This study found that NIMR has not been able to develop the requisite institutional capacity to carry out the mandate. NIMR should consider capacity building as a continuous process and not a one-off event. A programme should be put in place to ensure sustainability of the capacity building process. Certainly, qualified research scientists are not readily available on the job market, they have to be developed and sustained by having in place research facilities such as laboratories, equipment and research funding. Having trained such staff, they become precious resources that ought to be retained through some elaborate affirmative action. With the broad mandate that has been vested in NIMR, it is high time that capacity in M\&E and research management particularly that of intellectual property rights are prioritized and developed in order to maximize the benefits of research.

The main limitations of the current study are as a result of the experienced difficulty in obtaining comprehensive systematic data on both personnel and financial information, particularly on research funding, patents, consultancies, individual and institutional capacity building activities. Such information is not readily available and if available, it is scattered in many sources making it difficult to verify.

\section{Acknowledgements}

The authors acknowledge the Eastern and Southern African Management Institute and MsM Faculties and Consultants for sharing their knowledge and expertise. Mr. Peter Kiuluku is thanked for his availability and willingness to provide assistance whenever required to do so. Dr. Andrew Y. Kitua, former Director General of the National Institute for Medical Research, for his encouragement. We are particularly grateful to Dr Mwelecele Malecela, the then Director of Research Coordination and Promotion and current Director General, and Mr. Louis Kiluwa, the former Director of Finance and Administration for granting the authorization to access valuable information at NIMR. Our sincere thanks go to NIMR Centre Directors and staff who were kind enough to respond to the survey questionnaire, those who imparted valuable information to the study or shared their valuable time, expertise and experiences. We are grateful to Prof. Wen Kilama, the founding and first Director General of the National Institute for Medical Research, for 
supporting the study and providing his invaluable information and insights about the subject. Special thanks in particular should go to Messrs. Twaha Mlwilo and Filemoni Tenu for their help in data collection, management and analysis. Mr. Chotigunga C. Mdemu, Ms. Anna Kajange, Ms. Perpetua Maganga, Dr. William Kisinza, Mr. Charles Lusinde and Mr. Angelo Nkwera are thanked for assistance with access to information at NIMR. This study received financial support from the National Institute for Medical Research.

\section{References}

Adams, O. (1994) Re-profiling human resources: transferring care from hospital to community. Leadership in Health Services 3, 13-17.

Anonymous Editorial (2000) Strengthening research capacity's weakest link. The Lancet 358, 1381. Barret, E. \& Nakabugo, M.G. (2008) Irish-African Partnership for Research Capacity Building. An interim report on the findings of the first phase of the IAPRCB stakeholder consultation.

Condell, S.L. \& Begley, C. (2007) Capacity building: A concept analysis of the term applied to research. International Journal of Nursing Practice 13, 268-275.

Ericsson, K.A., Krampe, R.T. \& Tesch-Romer, C. (1993) The role of deliberate practice and acquisition of expert performance. Psychological Review 100, 363-406.

Government of Tanzania (1996) Ministry of Science, Technology and Higher Education. The National Science and Technology Policy for Tanzania, 1996.

Government of Tanzania (2000) Planning Commission, The Tanzania Development Vision 2025.

Government of Tanzania (2005) Vice Presidents Office, National Strategy for Growth and Reduction of Poverty (NSGRP).

Government of Tanzania (2009) National Website. Tanzania Country Profile 2009. Available from http//www.tanzania.go.tz/profilef.html.

Haines, A. (2003) Shaping the future of global health. Bulletin of the World Health Organization 81, 855 .

Hoffman, K.J., Kanyengo, C.W., Rapp, B.A. \& Kotzin, S. (2009) Mapping the health research landscape in Sub-Saharan Africa: a study of trends in biomedical publications. Journal of Medical Library Association 97, 41- 44.

Ijsselmuiden, C. (2007) Human resources for health research. Symposium of the Swiss Tropical Institute, 21 March 2007, MMS Bulletin 104, 22-27.

Kitua, A.Y. (2007) Health research in the new millennium: looking ahead. Tanzania Health Research Bulletin 9, 147-153.

Kitua, A.Y., Swai, G.B.R. \& Urio, T. (2002) Flows to health research institutions in Tanzania. In: Tanzania Strategic Research Series 2002. Tanzania Health Research Forum.

Lee, K., Walt, G. \& Haines, A. (2004) The challenge to improve global health: financing the Millennium Development Goals. Journal of American Medical Association 291, 2636-2638.

Mboera, L.E.G. (2010) NIMR at 30: History, Development, Achievements and Success Stories. National Institute for Medical Research, Dar es Salaam, Tanzania.

Mboera, L.E.G., Kilale, A.M., Manumbu, R.N., Kilima, S.P., Mwaseba, D.J.B., Range, N.S. \& Edwin, T. (2009) Evidence-Informed Policy Making and Priority Setting in the United Republic of Tanzania. National Institute for Medical Research, Dar es Salaam, Tanzania.

Merriam Webster (2009) Merriam Webster online search Dictionary, at www.merriamwebster.com retrieved on $2^{\text {nd }}$ August 2009.

Mfinanga, S.G.M., Sokoine, K., Ezekieli, L., Ngadaya, E., Mghamba, J. \& Ramaiya, K. (2011) Public health concern and initiatives on the priority action towards noncommunicable diseases in Tanzania. Tanzania Journal of Health Research 13 (Supl 1) doi: http://dx.doi.org/10.4314/thrb.v13i5.6

MoHSW (2009) Ministry of Health and Social Welfare. Health Sector Strategic Plan III July 2009 June 2015. "Partners for Delivering the MDGs" United Republic of Tanzania. 
Montorzi, G., de Haan S., IJsselmuiden, C. \& Mboera, L. (2009) Tanzania: An assessment of the health research system. A country report of the AHA series. Alignment and Harmonisation in Health Research. Council on Health Research for Development (COHRED).

Nchinda, T.C., (2002) Research Capacity strengthening in the South. Social Science \& Medicine 54, 1699-1711.

NIMR (1997) First Strategic Plan of the National Institute for Medical Research, Tanzania 1997 2002 .

NIMR (2002) Second Strategic Plan of the National Institute for Medical Research, Tanzania 2002 $-2008$.

NIMR (2008a) Third Strategic Plan of the National Institute for Medical Research, Tanzania 2008 2013.

NIMR (2008b) The Annual Report of the National Institute for Medical Research, 2007 - 2008. Dar es Salaam, Tanzania.

SAMRC (2008) South African Medical Research Council, Annual Report 2007/2008.

Shoo, J. (2009) Just 0.7 percent, but still a most welcome increment. The Guardian, 2009.

The Bamako Call to Action on Research for Health (2008) The Global Ministerial Forum on Research for Health Bamako, Mali, 17-19 November 2008.

United Nations (2008) The Millennium Development Goals Report, 2008. United Nations, New York.

URT (1979) Act of Parliament No. 23: An Act to establish the National Institute for Medical Research (NIMR) and to provide for the functions and powers of the Institute in relation to the promotion of medical research. United Republic of Tanzania.

Uthman, O.A. (2009) Performance, priorities, and future of biomedical research publications in Africa: Need for networks between scientists in developed and developing countries. Pan African Medical Journal 1 (5) (accessed at http://www.panafrican-medjournal.com/content/editorial/1/5/ on $16^{\text {th }}$ November 2009).

WHO (2009) The Algiers Declaration: Ministerial Conference on Research for Health in the African Region. Narrowing the knowledge gap to improve Africa's health. WHO Regional Office for Africa. 